\title{
Behavioral Medicine for Sedentary Behavior, Daily Physical Activity, and Exercise to Prevent Cardiovascular Disease: A Review
}

\author{
Mary Hannan ${ }^{1} \cdot$ Emily Kringle ${ }^{1} \cdot$ Cheuh-Lung Hwang ${ }^{2} \cdot$ Deepika Laddu $^{2}$ (D) \\ Accepted: 30 March 2021 / Published online: 6 July 2021 \\ (C) The Author(s), under exclusive licence to Springer Science+Business Media, LLC, part of Springer Nature 2021
}

\begin{abstract}
Purpose of Review Behavioral medicine is a multidisciplinary field that has a key role in reducing risk factors for cardiovascular disease (CVD). The purpose of this review is to describe the role of behavioral medicine for CVD prevention, using physical activity behaviors (e.g., sedentary behavior, daily physical activity, or exercise) as an exemplar. Application of behavioral medicine to improve dietary behaviors is also briefly discussed.

Recent Findings Behavioral medicine interventions that address physical activity behaviors are associated with improved cardiovascular risk factors. Interventions framed in behavior change theory that integrate behavior change techniques to reduce sedentary behavior and promote daily physical activity and exercise have similarly been applied to improve certain dietary behaviors and show promise for reducing CVD risk factors.

Summary Behavioral medicine has an important role in improving various physical activity behaviors for all populations, which is essential for preventing or managing CVD. Further investigation into behavioral medicine interventions that address personal, environmental, and social factors that influence participation in physical activity behaviors, as well as the adoption of a more optimal dietary pattern, is warranted.
\end{abstract}

Keywords Behavioral medicine $\cdot$ Cardiovascular disease $\cdot$ Prevention $\cdot$ Physical activity $\cdot$ Exercise $\cdot$ Sedentary behavior

\section{Introduction}

Atherosclerotic cardiovascular diseases (CVD), which include coronary heart disease, stroke, and peripheral artery disease, are leading causes of death in the USA and globally [1-4]. Despite

Mary Hannan and Emily Kringle are equal contributions as co-first authors.

This article is part of the Topical Collection on Nutrition

Deepika Laddu

dladdu@uic.edu

Mary Hannan

mhanna22@uic.edu

Emily Kringle

kringle@uic.edu

Cheuh-Lung Hwang

clhwang@uic.edu

1 Department of Medicine, College of Medicine, University of Illinois at Chicago, Chicago, IL, USA

2 Department of Physical Therapy, College of Applied Health Sciences, University of Illinois at Chicago, 1919 W. Taylor Street (MC 898), Chicago, IL, USA a steady decline in CVD mortality over the past decade, cardiovascular health has not improved [5]. This stagnated progress foreshadows increasing incidence and prevalence of CVD expected across most racial and ethnic groups in the coming years [6]. Nearly a quarter of CVD-related deaths are preventable by addressing modifiable cardiovascular health behaviors such as insufficient physical activity and diet [7]. Behavioral medicine interventions therefore play a key role in addressing cardiovascular risk behaviors. The purpose of this review is to define the role of behavioral medicine, using physical activity behaviors as an exemplar, for cardiovascular disease prevention. In this brief review, we will define physical activity behaviors (sedentary behavior, daily physical activity, and exercise) and describe the role of behavioral medicine in optimizing physical activity behaviors. We will also briefly describe the current evidence for behavioral medicine interventions that address physical activity and diet to improve cardiovascular health.

\section{What Are Physical Activity Behaviors?}

Broadly, the term physical activity behavior encompasses bodily movement that can be classified by purpose or intent, 
intensity (or lack thereof), posture, or energy expenditure [8]. Sedentary behavior is characterized by a seated or reclined posture and very low levels of energy expenditure [9]. Daily physical activity is accumulated through engaging in the activities that make up daily life. This type of activity is referred to by several names in the physical activity literature, including but not limited to non-exercise physical activity, habitual physical activity, leisure-time physical activity, occupational physical activity, and daily physical activity [8]. Examples of daily accumulated physical activity include the total time spent preparing a meal, taking the dog for a walk, biking to commute to work, and playing basketball with friends. These activities encompass physical activity at all intensities (light to vigorous) that can benefit cardiovascular health. Exercise is planned, structured, repetitive activity that is completed for the explicit purpose of fitness [10]. Sedentary behavior, daily physical activity, and exercise each play an independent role in health and risk factors for CVD.

\section{What Is the Relationship Between Physical Activity Behaviors and CVD?}

Mounting evidence suggests increased sedentary behavior is associated with greater risk for CVD, diabetes, certain cancers, obesity, and premature mortality [11, 12]. High levels of sedentary behavior are also associated with elevated risk for CVD events and CVD mortality, even after controlling for time spent in moderate to vigorous physical activity $[13,14$, 15•]. Consequently, several studies have shown that displacing sedentary behavior with moderate to vigorous physical activity [16-19] or even light physical activity [18] may confer significant and clinically important improvements on the cardiometabolic profile, through its effect on body mass index (BMI), waist circumference, high density lipoprotein (HDL) cholesterol, fasting glucose, and fasting insulin. Further, among people with high levels of sedentary behavior (more than $6 \mathrm{~h}$ per day), displacing sedentary time with standing [16] or light intensity physical activity [17] was associated with reduced CVD mortality risk. Individuals with chronic health conditions or disabilities may experience significant barriers to physical activity and exercise [20-22]. These individuals may derive health benefits from displacing sedentary time with standing or light or moderate physical activities as an achievable first step toward improving cardiovascular health [23-25]. This evidence that sedentary behavior is a risk factor for CVD, independent of physical activity, supports the need to focus on sedentary behavior as a novel and independent behavioral target for interventions.

There is strong evidence supporting the cardiovascular health benefits associated with daily physical activity and exercise. Population-based studies have demonstrated that high levels of daily physical activity are associated with optimal waist circumference, HDL cholesterol, triglycerides, and a lower risk of experiencing a cardiovascular event and CVD mortality [26-29]. Exercise in itself has positive physiologic effects on cardiovascular health, including but not limited to its impact on coagulation, fibrinolysis, vascular remodeling, blood pressure, and lipids [30]. Given the overwhelming evidence supporting effectiveness of physical activity or exercise for the primary prevention of CVD, national and global public health guidelines speak to each type of physical activity behavior (Table 1). Furthermore, physical activity is a common component of secondary prevention programs for adults with CVD risk factors and diagnosed CVD. Physical activity recommendations that provide specific guidelines within these populations are available $[41,42]$. In general, there is a consensus that achieving 150 min per week of moderate to vigorous physical activity is associated with significant cardiometabolic and overall health benefits (Table 1). However, among populations with chronic disease and those who are inactive, lower volumes of physical activity and exercise and small increases in activity may importantly improve cardiovascular health and reduce mortality risk [43].

\section{Adherence to Physical Activity Guidelines}

Despite consistent and compelling evidence of the health benefits of physical activity, adherence to physical activity guidelines is poor. Though insufficient physical activity trends persist $[44,45]$, the greater concern, perhaps, may be the high prevalence of sedentary behaviors observed among all ages [46]. Recent analyses of the National Health and Nutrition Examination Survey (NHANES) revealed no change in adherence to physical activity guidelines between 2007 to 2008 (63\%) and 2015 to $2016(65 \%)$, and a significant increase in sedentary behavior between 2007 and 2014 (5.7 to $6.4 \mathrm{~h} /$ day) [45]. Of particular concern, adults with CVD diagnoses are more likely to demonstrate persistent low levels of physical activity and high levels of sedentary behavior [47-49]. Mounting evidence for the detrimental impacts of prolonged sedentary time has been the impetus for the World Health Organization (WHO) to recommend minimizing sedentary behavior as part of the 2020 Global Physical Activity Guidelines [40•]. Coincidentally, recommendations by the WHO for physical activity and sedentary behaviors echo the messaging, "sit less and move more" that has been emphasized in several national and public health guidelines [31, 32, 38, 39]. Behavioral medicine plays a distinct role in promoting physical activity behaviors and supporting long-term adherence to physical activity guidelines through tailored person-centered interventions that account for diverse personal, environmental, and social factors. 


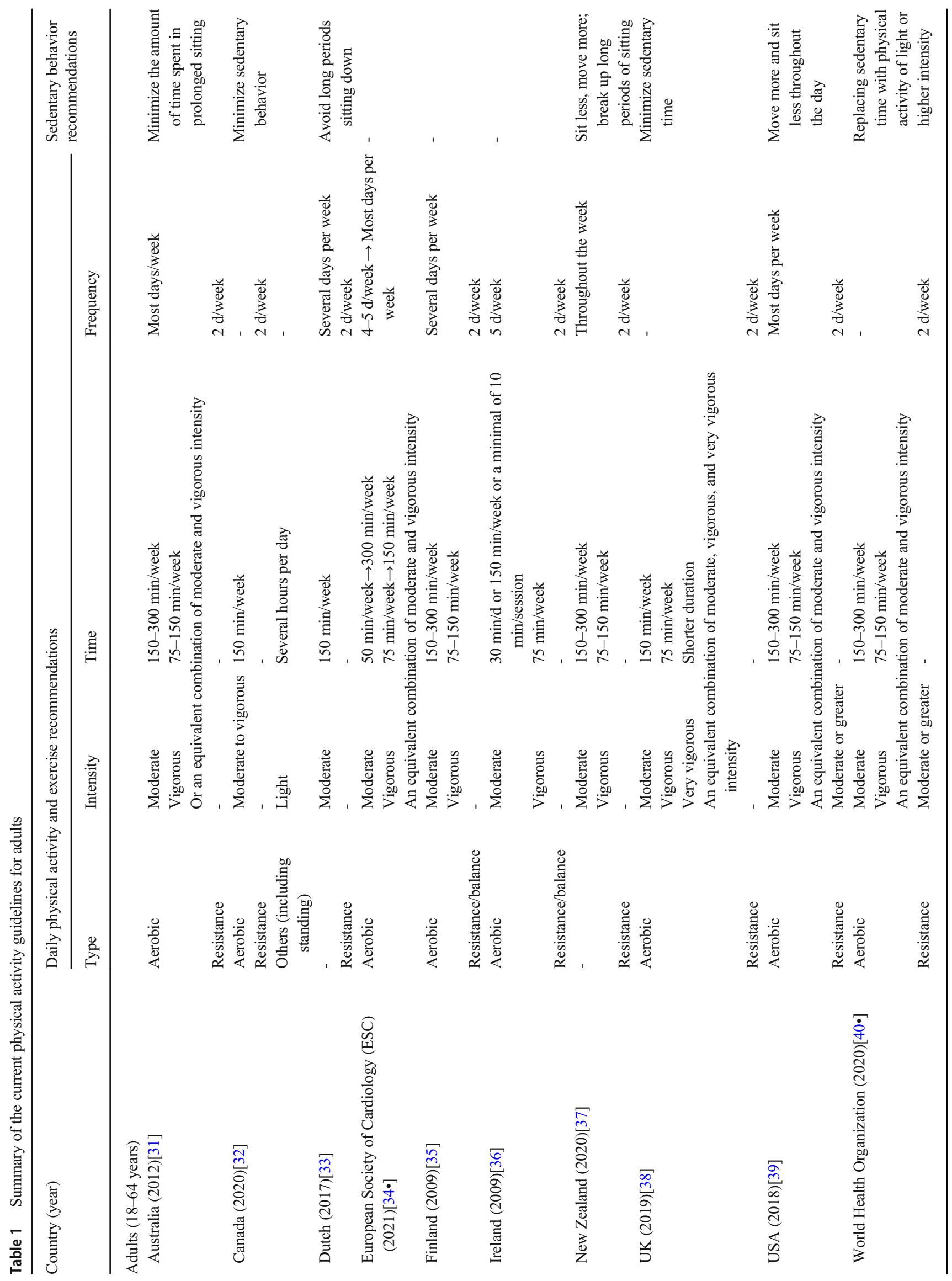




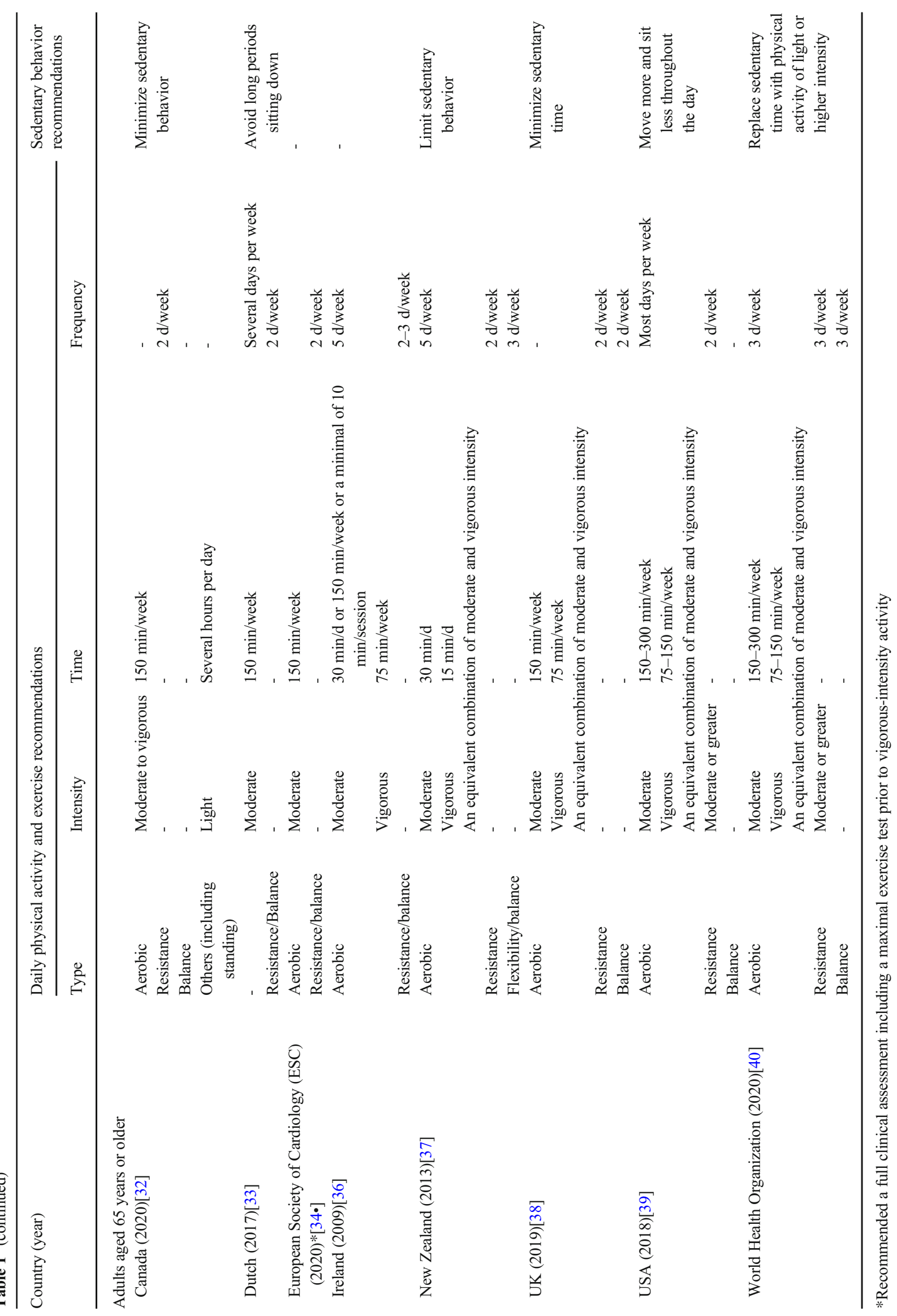


What Is Behavioral Medicine's Role in Physical Activity?

Behavioral medicine is a multidisciplinary field that leverages interventions focused on behaviors, psychosocial factors, and the biological sciences to improve health conditions across the lifespan $[50,51]$. This field has played a central role in linking behavior with health over the past 70 years, including elucidating the profound impact of behaviors such as physical activity on CVD outcomes [52]. A broad range of people can derive benefit from cardiac behavioral medicine interventions, including people with or without CVD and people at risk for CVD [51]. The unique role of behavioral medicine in promoting cardiovascular health is the use of behavior change techniques (such as those described by Michie and colleagues in [53]) to facilitate healthy active lifestyles. Underlying the selection of behavior change techniques are theories of health behavior change. For example, interventions based in Social Cognitive Theory may enhance self-efficacy for participating in exercise classes [54], while an intervention based in the Transtheoretical Model may use decisional balance strategies to facilitate motivation for participating in exercise classes $[55,56]$. Person-centered interventions that address personal, environmental, and social barriers are the core of behavioral medicine. Theories of health behavior change allow interventions to be tailored to overcome barriers unique to each individual. The provider's role in behavioral medicine interventions is to screen and, if indicated, deliver brief office-based intervention [57•]. The provider may also screen and refer patients to other members of the healthcare team who have training in these interventions (e.g., nurse, occupational therapist, health coach, psychologist).

\section{Behavioral Medicine Interventions for Sedentary Behavior and Physical Activity}

\section{Sedentary Behavior}

Sedentary time is accumulated during common daily activities: workplace/desk jobs, television watching or screen time, transportation, and leisure activities [58]. These activities are context-specific and habitual in nature, and large amounts of sedentary time can be accumulated without conscious awareness $[59,60]$. Thus, reducing sedentary behavior may require distinct behavioral intervention approaches that specifically target sedentary activities. In fact, a systematic review identified that interventions designed to specifically address sedentary behavior are more effective than interventions designed to address both sedentary behavior and physical activity simultaneously [61]. Behavioral interventions that address sedentary behavior may seek to reduce the total duration of sedentary time or to disrupt prolonged periods of sedentary time with brief periods of light, moderate, or vigorous intensity physical activity [62]. A recent Cochrane review reported on an array of behavior change techniques that are associated with reduction in non-workplace sedentary behavior among older adults [63]. Among the techniques examined, selfmonitoring [64] and app-based interventions that use multiple behavior change techniques [65] were promising for reducing sedentary behavior. However, the short-term nature and quality of these studies offer uncertain evidence of behavior change and weak evidence for changes in CVD risk factors and CVD outcomes. Counseling and education-based interventions that focus on reducing screen-time sedentary behavior also show promise for reducing body mass index [66]. The most abundant literature in sedentary behavior interventions addresses occupational sedentary time. These interventions leverage a combination of environmental modification and behavior change. A meta-analysis that examined the effects of movement-permissive workstations (e.g., standing desks and cycle ergometers) identified a reduction in sedentary time of $77 \mathrm{~min}$ per 8-h workday [67]. Among the six studies that reported on waist circumference as a secondary outcome, five reported an improvement in waist circumference. Furthermore, workers who are overweight or obese may derive greater cardiovascular benefits from sit-to-stand workstations than workers who are not overweight or obese [68]. Further research is needed that examines the impact of sedentary behavior interventions across contexts (occupational and non-occupational) on CVD risk factors.

\section{Daily Physical Activity}

Daily physical activity can be used to displace or break up prolonged sedentary time. Daily physical activity is accumulated through engagement in numerous activities that encompass the full range of intensity: light, moderate, and vigorous physical activity. Physical activity guidelines speak to this full range (Table 1), and as such, daily physical activity is viewed as a critically important target for cardiovascular health. Findings from epidemiological studies have further demonstrated that more steps per day are associated reduced CVD risk, CVD incidence, and CVD mortality [69]. Although physical activity guidelines do not prescribe minimum step count recommendations, the ease of monitoring step countrelated goals has supported the development of walking interventions [70]. Other behavioral medicine approaches emphasize lifestyle-based behavior change to increase the amount of light or moderate physical activity that is accumulated through the basic and instrumental activities of daily living [71]. Behavioral medicine interventions that use counseling approaches to address daily physical activity have shown to be effective at improving CVD risk factors as part of primary $[57 \bullet, 72]$ and secondary prevention [73] of CVD. Behavior change techniques applied through counseling generally apply 
frameworks grounded in behavior change theories. A metaanalysis of physical activity interventions reported that the Transtheoretical Model, Social Cognitive Theory, and the Theory of Planned Behavior were the most frequently used to promote physical activity, and no theory was superior to the others [74]. Multi-component interventions that included goal setting and at least one additional behavior change technique (such as feedback or planning) were associated with moderate effects on daily physical activity levels assessed by pedometer and self-report measures [75]. A separate meta-analysis identified that physical activity interventions that aimed to enhance knowledge, attitudes, and skills may lead to improvements in body weight, blood pressure, total cholesterol, triglycerides, and CVD risk profile [76]. Optimal delivery modes (i.e., faceto-face, remote) and intervention intensity (i.e., brief counseling versus multiple face-to-face visits) continue to be explored $[77,78]$. Long-term adherence to optimal daily physical activity levels may be achievable with patient-centered referrals [79], but further research on strategies for long-term adherence is needed $[80,81]$.

\section{Exercise}

In addition to daily physical activity, national and global physical activity guidelines recommend that adults participate in exercise, including aerobic exercise and resistance training, for overall health and the prevention of CVD (Table 1) [82•, 83]. Behavioral interventions that promote exercise participation for the prevention of CVD are guided by behavior change techniques, including but not limited to overcoming barriers, enhancing self-efficacy, action planning, developing coping skills, and evaluating intention [84-86]. Studies that employ exercise-based behavioral interventions conventionally focus on optimizing exercise dose. An appropriately dosed exercise prescription is based on four factors: frequency, intensity, duration, and type of exercise $[82 \bullet, 87 \bullet]$. Exercise, particularly when performed at the "appropriate dose," has been shown to positively influence certain CVD risk factors [88].

Supervised exercise interventions are often prescribed to increase levels of physical activity and improve cardiovascular health for individuals with or at risk for CVD [87•, 89-91]. Among the most empirically supported and evidence-based programs is cardiovascular rehabilitation, which is sometimes referred to as cardiac rehabilitation. Cardiovascular rehabilitation programs are recommended for individuals with CVD (including heart failure) $[92,93]$ and are associated with improved clinical outcomes $[94,95]$. Cardiovascular rehabilitation is a comprehensive program that includes tailored, individualized exercise prescriptions guided by assessment and individualized goals [87•]. A critical component of cardiovascular rehabilitation programs is behavioral counseling, which is used to explore key behavioral factors to promote engagement in physical activity, including motivational interviewing, goal setting, coping strategies, understanding facilitators and addressing barriers, and problem-solving strategies to integrate physical activity into daily life [87•]. In the context of these behavioral factors, an exercise program is dosed in a personalized, tailored manner [87•].

Despite clear guidelines delineating recommended levels of exercise (Table 1) and the success of supervised exercise programs, like cardiovascular rehabilitation, in improving CVD risk factors, individuals often do not meet the physical activity guidelines [45]. This may be due to difficulty with initiation, adoption, and adherence to exercise programs for individuals with or at risk for CVD. The ideal method of referral to supervised and structured exercise programs to promote adoption and adherence is not known [57•, 96-99]. Exercise referrals by primary care providers have been associated with trends toward increased levels of physical activity, but these findings, while important, were not statistically significant [99]. Despite well-established clinical benefits, support by national health agencies, and clear referral mechanisms, participation in cardiovascular rehabilitation programs remains extremely low [100], which has prompted research on identifying barriers to enrollment and strategies to enhance participation [101, 102].

Behavioral medicine has an important role in the development and evaluation of interventions to promote long-term participation in supervised exercise programs [103]. Selfefficacy and, particularly, autonomous motivation have been identified as factors that may influence long-term participation in exercise programs for individuals with established CVD [104]. Self-regulatory efficacy and its relationship to adherence have also been proposed as areas to address to promote continued participation in cardiovascular rehabilitation [105]. Perceived barriers influence intention and participation, so these factors may also need to be addressed to encourage continued participation in cardiovascular rehabilitation programs [84]. It was recently reported that women had significantly lower adherence rates than men in cardiovascular rehabilitation, which highlights an important area where further investigation and tailored interventions are needed [106]. Future research on interventions to promote long-term participation in supervised exercise programs is vitally needed, particularly focusing on the role of theory-guided behavior change techniques that address personal, social, and environmental factors $[85,103]$.

\section{Behavioral Interventions that Address Physical Activity and Diet}

A recent meta-analysis identified that adherence to multiple healthy lifestyle behaviors, such as physical activity and healthy diet patterns, is associated with a $66 \%$ greater reduction in CVD risk factors than adherence to one or no healthy 
lifestyle behaviors [107]. Healthy dietary patterns include the Mediterranean-style diet or, similarly, those that emphasize higher intakes of plant-based foods, whole-grains, lean meats, seafood, and foods with healthy fat sources (e.g., nuts, unsaturated vegetable oils) and lower intakes of processed meats, sugar-sweetened foods and beverages, and refined grains [108]. Adoption of favorable dietary patterns, in addition to physical activity or exercise, is recognized as a critical strategy to improve cardiovascular health and reduce risk of CVD and related comorbidities [7]. As such, the US Preventive Task Force has identified that behavioral medicine interventions that promote physical activity and healthful diet patterns are likely to be effective at improving CVD risk factors (e.g., blood pressure, cholesterol, glucose, and adiposity) among adults with and without elevated CVD risk factors [7, 72, 73]. Given the strong evidence base, it is clear why wellestablished supervised exercise intervention programs (i.e., cardiovascular rehabilitation) integrate diet and nutrition counseling as a core component to promote cardiovascular health [87•]. Accordingly, there is an overlap among specific behavior change techniques that influence physical activity behaviors and diet patterns. Specifically, motivational interviewing, goal setting, problem solving, feedback on behavior, and social support are critical techniques of theorydriven interventions that are considered to effectively modify both behaviors [72, 73, 109-111]. Further, interventions that include the use of adding objects to the environment and social comparison were identified as key behavior change techniques to promote healthy dietary patterns [111]. Further research in this area should focus on optimizing intervention dose and identifying specific behavior change techniques that improve intervention efficacy, which is necessary to promote and maintain meaningful changes in dietary behaviors. Furthermore, it is critical to account for individual social determinants of health that impact adoption, implementation, and translation of interventions targeting diet, across the diverse populations served in clinical practice [112].

\section{Future Directions}

Behavioral medicine has made profound contributions to the prevention of CVD with interventions that promote behavior change for physical activity and diet behaviors. In this brief review, we focused on behavioral techniques to improve physical activity behaviors (inclusive of interventions that address both physical activity and diet) that have potentially important implications for CVD risk management. However, further research is needed. Theory-driven behavior change techniques can facilitate "sitting less and moving more," but behavior change takes time and requires active participation and communication between providers and patients. Investigation into behavior change techniques to reduce sedentary behavior and increase physical activity that occur in community-based environments is vital, particularly in the context of global pandemics, such as the COVID-19 pandemic [113]. Further, there is a great need for exploration into behavioral factors that facilitate promotion of long-term maintenance of reduced sedentary time and increased physical activity. Given the tremendous growth of technology, there is great opportunity to integrate behavior change techniques into electronic and mobile health supported interventions to reduce sedentary behavior and promote physical activity for CVD risk reduction in various high-risk populations [114]. Finally, there is a critical need to advance the science on the most appropriate behavior change techniques that can be applied to vulnerable, diverse, and under-resourced populations; such research may consider unique patient-specific environmental and social factors to promote health equity for the prevention of CVD $[112,115]$.

\section{Conclusion}

CVD is a common and pervasive disease that can be prevented by reducing risk factors with behavior modification. Behavioral medicine has a critical role in CVD risk factor reduction. Interventions grounded in behavior change theory have demonstrated success at reducing sedentary behavior and promoting physical activity. Similar approaches have been used in physical activity interventions that also address diet. However, low adherence to physical activity guidelines persists. There is a substantial opportunity for adoption and integration of patient-centered personalized behavioral interventions that effectively promote behavior change related to sedentary behavior and physical activity, as well as diet, for the prevention and management of CVD.

Funding Research reported in this publication was supported by the National Heart, Lung, and Blood Institute (M. Hannan and E. Kringle, Award Number T32HL134634; D. Laddu, Award Number K01HL148503), and by the by the National Institute on Alcohol Abuse and Alcoholism (C.L. Hwang, Award Number K99AA028537). The content is solely the responsibility of the authors and does not necessarily represent the official views of the National Institutes of Health. M. Hannan is also supported by the Robert Wood Johnson Foundation as a Future of Nursing Scholar Postdoctoral Fellow. The views expressed here do not necessarily reflect the views of the Foundation.

\section{Declarations}

Conflict of Interest The authors declare no competing interests.

Human and Animal Rights and Informed Consent This article does not contain any studies with human or animal subjects performed by any of the authors. 


\section{References}

Papers of particular interest, published recently, have been highlighted as:

- Of importance

1. Centers for Disease C, Prevention. FastStats - Leading causes of death. https://www.cdc.gov/nchs/fastats/leading-causes-of-death. htm 2020. Accessed 2 Dec 2020.

2. Centers for Disease C, Prevention. Vital signs: preventable deaths from heart disease and stroke. https://www.cdc.gov/dhdsp/vital signs.htm 2018. Accessed 28 Dec 2020.

3. Centers for Disease Control and Prevention Heart Disease Facts. https://www.cdc.gov/heartdisease/facts.htm 2020. Accessed 28 Dec 2020.

4. Virani SS, Alonso A, Aparicio HJ, Benjamin EJ, Bittencourt MS, Callaway CW, et al. Heart disease and stroke statistics-2020 update: a report from the American Heart Association. Circulation. 2021;143(8):e254-743. https://doi.org/10.1161/CIR. 0000000000000950 .

5. Shah N, Lloyd-Jones D, O'Flaherty M, Capewell S, Kershaw K, Carnethon M, et al. Trends in cardiometabolic mortality in the United States, 1999-2017. JAMA. 2019;322(8):780-2. https:// doi.org/10.1001/jama.2019.9161.

6. Pearson-Stuttard J, Guzman-Castillo M, Penalvo J, Rhem C, Afshin A, Danaei G, et al. Modeling future cardiovascular disease mortality in the United States: national trends and racial and ethnic disparities. Circulation. 2016;133:967-78. https://doi.org/10. 1161/CIRCULATIONAHA.115.019904.

7. Han L, You D, Ma W, Astell-Burt T, Feng X, Duan S, et al. National trends in American Heart Association Revised Life's Simple 7 metrics associated with risk of mortality among US adults. JAMA Netw Open. 2019;2(10):e1913131. https://doi.org/ 10.1001/jamanetworkopen.2019.13131.

8. Thivel D, Tremblay A, Genin PM, Panahi S, Rivière D, Duclos M. Physical activity, inactivity, and sedentary behaviors: definitions and implications in occupational health. Front Public Health. 2018;6:288.

9. Tremblay MS, Aubert S, Barnes JD, Saunders TJ, Carson V, Latimer-Cheung AE, et al. Sedentary behavior research network (SBRN)-terminology consensus project process and outcome. Int J Behav Nutr Phys Act. 2017;14(75):75.

10. Caspersen CJ, Powell KE, Christenson GM. Physical activity, exercise, and physical fitness: definitions and distinctions for health-related research. Public Health Rep. 1985;100(2):126-31.

11. Thorp AA, Owen N, Neuhaus M, Dunstan DW. Sedentary behaviors and subsequent health outcomes in adults: a systematic review of longitudinal studies, 1996-2011. Am J Prev Med. 2011;41(2): 207-15.

12. Wilmot EG, Edwardson CL, Achana FA, Davies MJ, Gorely T, Gray LJ, et al. Sedentary time in adults and the association with diabetes, cardiovascular disease and death: systematic review and meta-analysis. Diabetologia. 2012;55(11):2895-905.

13. Patterson R, McNamara E, Tainio M, de Sá TH, Smith AD, Sharp SJ, et al. Sedentary behaviour and risk of all-cause, cardiovascular and cancer mortality, and incident type 2 diabetes: a systematic review and dose response meta-analysis. Eur J Epidemiol. 2018;33(9):811-29.

14. Ekelund U, Steene-Johannessen J, Brown WJ, Fagerland MW, Owen N, Powell KE, et al. Does physical activity attenuate, or even eliminate, the detrimental association of sitting time with mortality? A harmonised meta-analysis of data from more than 1 million men and women. Lancet. 2016;388(10051):1302-10.
15. Young DR, Hivert M-F, Alhassan S, Camhi SM, Ferguson JF, Katzmarzyk PT, et al. Sedentary behavior and cardiovascular morbidity and mortality: a science advisory from the American Heart Association. Circulation. 2016;134(13):e262-79 American Heart Association statement on current evidence describing the prevalence, cardiovascular disease risk, and interventions for sedentary behavior.

16. Stamatakis E, Gale J, Bauman A, Ekelund U, Hamer M, Ding D. Sitting time, physical activity, and risk of mortality in adults. J Am Coll Cardiol. 2019;73(16):2062-72.

17. Dohrn M, Kwak L, Oja P, Sjöström M, Hagströmer M. Replacing sedentary time with physical activity: a 15-year follow-up of mortality in a national cohort. Clin Epidemiol. 2018;10:179-86.

18. del Pozo-Cruz J, García-Hermoso A, Alfonso-Rosa RM, AlvarezBarbosa F, Owen N, Chastin S, et al. Replacing sedentary time: meta-analysis of objective-assessment studies. Am J Prev Med. 2018;55(3):395-402.

19. Buman MP, Winkler EA, Kurka JM, Hekler EB, Baldwin CM, Owen N, et al. Reallocating time to sleep, sedentary behaviors, or active behaviors: associations with cardiovascular disease risk biomarkers, NHANES 2005-2006. Am J Epidemiol. 2013;179(3): 323-34.

20. Hannan M, Bronas UG. Barriers to exercise for patients with renal disease: an integrative review. J Nephrol. 2017;30:729-41. https:// doi.org/10.1007/s40620-017-0420-z.

21. Mulligan HF, Hale LA, Whitehead L, Baxter GD. Barriers to physical activity for people with long-term neurological conditions: a review study. Adapt Phys Act Q. 2012;29(3):243-65. https://doi.org/10.1123/apaq.29.3.243.

22. Nicholson S, Sniehotta FF, van Wijck F, Greig CA, Johnston M, McMurdo ME, et al. A systematic review of perceived barriers and motivators to physical activity after stroke. Int J Stroke. 2013;8(5):357-64. https://doi.org/10.1111/j.1747-4949.2012. 00880.x.

23. Morton S, Fitzsimons C, Hall J, Clarke D, Forster A, English C, et al. Sedentary behavior after stroke: a new target for therapeutic intervention. Int J Stroke. 2018;14(1):9-11. https://doi.org/10. $1177 / 1747493018784505$.

24. Dempsey PC, Friedenreich CM, Leitzmann MF, Buman MP, Lambert E, Willumsen J, et al. Global public health guidelines on physical activity and sedentary behavior for people living with chronic conditions: a call to action. J Phys Act Health. 2020;18(1): $76-85$.

25. Healy GN, Winkler EA, Owen N, Anuradha S, Dunstan DW. Replacing sitting time with standing or stepping: associations with cardio-metabolic risk biomarkers. Eur Heart J. 2015;36(39):26439.

26. Ekblom-Bak E, Ekblom B, Vikström M, de Faire U, Hellénius ML. The importance of non-exercise physical activity for cardiovascular health and longevity. Br J Sports Med. 2014;48(3):233-8.

27. Hamer M, de Oliveira C, Demakakos P. Non-exercise physical activity and survival: English longitudinal study of ageing. Am J Prev Med. 2014;47(4):452-60.

28. Lin H, Sardana M, Zhang Y, Liu C, Trinquart L, Benjamin EJ, et al. Association of habitual physical activity with cardiovascular disease risk. Circ Res. 2020;127(10):1253-60.

29. Batacan RB, Duncan MJ, Dalbo VJ, Tucker PS. Fenning AS (2015) Effects of light intensity activity on CVD risk factors: a systematic review of intervention studies. Biomed Res Int. 2015;2015:1-10.

30. Buttar HS, Li T, Ravi N. Prevention of cardiovascular diseases: role of exercise, dietary interventions, obesity and smoking cessation. Exp Clin Cardiol. 2005;10(4):229-49.

31. Brown WJ, Bauman AE, Bull F, Burton NW. Development of evidence-based physical activity recommendations for adults 
(18-64 years). Report prepared for the Australian Government Department of Health, August 2012. 2013.

32. Ross R, Chaput J-P, Giangregorio LM, Janssen I, Saunders TJ, Kho ME, et al. Canadian 24-hour movement guidelines for adults aged 18-64 years and adults aged 65 years or older: an integration of physical activity, sedentary behaviour, and sleep. Appl Physiol Nutr Metab. 2020;45(10):S57-S102.

33. Weggemans RM, Backx FJG, Borghouts L, Chinapaw M, Hopman MTE, Koster A, et al. The 2017 Dutch Physical Activity Guidelines. Int J Behav Nutr Phys Act. 2018;15(1):58. https://doi.org/10.1186/s12966-018-0661-9.

34. Pelliccia A, Sharma S, Gati S, Bäck M, Börjesson M, Caselli S, et al. 2020 ESC Guidelines on sports cardiology and exercise in patients with cardiovascular disease. Eur Heart J. 2021;42(1):1796. https://doi.org/10.1093/eurheartj/ehaa605 European Society of Cardiology recommendations for physical activity among adults with CVD.

35. The Physical Activity Pie. UKK Institute. 2009. https:// ukkinstituutti.fi/wp-content/uploads/2020/10/image-17.jpeg Accessed 25 Feb 2021.

36. The National Guidelines on Physical Activity for Ireland. Department of Health and Children. Dublin: Health Service Executive; 2009

37. Guidelines on Physical Activity for Older People (aged 65 years and over). Ministry of Health, Wellington. 2013.

38. Gibson-Moore H. UK Chief Medical Officers' physical activity guidelines 2019: what's new and how can we get people more active? Nutr Bull. 2019;44(4):320-8.

39. U.S. Department of Health and Human Services. Physical activity guidelines for Americans. Washington, DC. 2018.

40. WHO Guidelines on Physical Activity and Sedentary Behavior. Geneva: World Health Organization; 2020. World Health Organization guidelines on physical activity and sedentary behavior.

41. Billinger SA, Arena R, Bernhardt J, Eng JJ, Franklin BA, Johnson $\mathrm{CM}$, et al. Physical activity and exercise recommendations for stroke survivors: a statement for healthcare professionals from the American Heart Association/American Stroke Association. Stroke. 2014;45(8):2532-53.

42. Sharma S, Gati S, Collet J-P, Corrado D, Drezner JA, Heidbuchel $\mathrm{H}$, et al. $2020 \mathrm{ESC}$ Guidelines on sports cardiology and exercise in patients with cardiovascular disease. Eur Heart J. 2021;42:17 ̀̀96.

43. Warburton DE, Bredin SS. Reflections on physical activity and health: what should we recommend? Can J Cardiol. 2016;32(4): 495-504.

44. Guthold R, Stevens GA, Riley LM, Bull FC. Worldwide trends in insufficient physical activity from 2001 to 2016 : a pooled analysis of 358 population-based surveys with 1.9 million participants. Lancet Glob Health. 2018;6(10):e1077-86.

45. Du Y, Liu B, Sun Y, Snetselaar LG, Wallace RB, Bao W. Trends in adherence to the physical activity guidelines for Americans for aerobic activity and time spent on sedentary behavior among US adults, 2007 to 2016. JAMA Netw Open. 2019;2(7):e197597.

46. Ng SW, Popkin BM. Time use and physical activity: a shift away from movement across the globe. Obes Rev. 2012;13(8):659-80.

47. English C, Healy GN, Coates A, Lewis L, Olds T, Bernhardt J. Sitting and activity time in people with stroke. Phys Ther. 2016;96(2):193-201.

48. Gerage AM, Correia MA, Oliveira PML, Palmeira AC, Domingues WJR, Zeratti AE, et al. Physical activity levels in peripheral artery disease patients. Arq Bras Cardiol. 2019;113(3):410-6.

49. Reid RD, Morrin LI, Pipe AL, Dafoe WA, Higginson LA, Wielgosz AT, et al. Determinants of physical activity after hospitalization for coronary artery disease: the Tracking Exercise After Cardiac Hospitalization (TEACH) Study. Eur J Cardiovasc Prev
Rehabil. 2006;13(4):529-37. https://doi.org/10.1097/01.hjr. 0000201513.13343.97.

50. Society of Behavioral Medicine. What is behavioral medicine? 2020. https://www.sbm.org/about/behavioral-medicine. Accessed 12-18-2020.

51. Graves KD, Miller PM. Behavioral medicine in the prevention and treatment of cardiovascular disease. Behav Modif. 2003;27(1):325. https://doi.org/10.1177/0145445502238690.

52. Fisher EB, Fitzgibbon ML, Glasgow RE, Haire-Joshu D, Hayman LL, Kaplan RM, et al. Behavior matters. Am J Prev Med. 2011;40(5):e15-30. https://doi.org/10.1016/j.amepre.2010.12. 031.

53. Michie S, Richardson M, Johnston M, Abraham C, Francis J, Hardeman $\mathrm{W}$, et al. The behavior change technique taxonomy (v1) of 93 hierarchically clustered techniques: building an international consensus for the reporting of behavior change interventions. Ann Behav Med. 2013;46(1):81-95.

54. Bandura A. Health promotion by social cognitive means. Health Educ Behav. 2004;31(2):143-64.

55. Hutchison AJ, Breckon JD, Johnston LH. Physical activity behavior change interventions based on the transtheoretical model: a systematic review. Health Educ Behav. 2009;36(5):829-45.

56. Prochaska JO, Redding CA, Evers KE. The transtheoretical model and stages of change. In: Glanz K, Rimer B, Viswanath K, editors. Health behavior: theory, research, and practice. 5th ed. San Francisco: Jossey-Bass; 2015. p. 125-48.

57. Lobelo F, Rohm Young D, Sallis R, Garber MD, Billinger SA, Duperly J, et al. Routine assessment and promotion of physical activity in healthcare settings: a scientific statement from the American Heart Association. Circulation. 2018;137(18):e495522 This statement provides an overview of factors associated with the assessment and promotion of physical activity.

58. Henschel B, Gorczyca A, Chomistek A. Time spent sitting as an independent risk factor for cardiovascular disease. Am J Lifestyle Med. 2020;14(2):204-15.

59. Conroy D, Maher J, Elavsky S, Hyde A, Doerksen S. Sedentary behavior as a daily process regulated by habits and intentions. Health Psychol. 2013;32(11):1149-57.

60. Maher J, Conroy D. A dual-process model of older adults' sedentary behavior. Health Psychol. 2016;35(3):262-72.

61. Prince S, Saunders T, Gresty K, Reid R. A comparison of the effectiveness of physical activity and sedentary behaviour interventions in reducing sedentary time in adults: a systematic review and meta-analysis of controlled trials. Obes Rev. 2014;15(11): 905-19.

62. Saunders TJ, McIsaac T, Douillette K, Gaulton N, Hunter S, Rhodes RE, et al. Sedentary behaviour and health in adults: an overview of systematic reviews. Appl Physiol Nutr Metab. 2020;45(10):S197-217.

63. Murtagh EM, Murphy MH, Milton K, Roberts NW, O'Gorman $\mathrm{CS}$, Foster $\mathrm{C}$. Interventions outside the workplace for reducing sedentary behaviour in adults under 60 years of age. Cochrane Database Syst Rev. 2020;7(7):CD012554.

64. Compernolle S, DeSmet A, Poppe L, Crombez G, De Bourdeaudhuij I, Cardon G, et al. Effectiveness of interventions using self-monitoring to reduce sedentary behavior in adults: a systematic review and meta-analysis. Int J Behav Nutr Phys Act. 2019;16(1):63.

65. Dunn EE, Gainforth HL, Robertson-Wilson JE. Behavior change techniques in mobile applications for sedentary behavior. Digit Health. 2018;4:2055207618785798.

66. Wu L, Sun S, He Y, Jiang B. The effect of interventions targeting screen time reduction: A systematic review and meta-analysis. Medicine (Baltimore). 2016;95(27):e4029. https://doi.org/10. 1097/MD.0000000000004029. 
67. Neuhaus M, Eakin EG, Straker L, Owen N, Dunstan DW, Reid N, et al. Reducing occupational sedentary time: a systematic review and meta-analysis of evidence on activity-permissive workstations. Obes Rev. 2014;15(10):822-38.

68. Chambers AJ, Robertson MM, Baker NA. The effect of sit-stand desks on office worker behavioral and health outcomes: a scoping review. Appl Ergon. 2019;78:37-53.

69. Hall KS, Hyde ET, Bassett DR, Carlson SA, Carnethon MR, Ekelund U, et al. Systematic review of the prospective association of daily step counts with risk of mortality, cardiovascular disease, and dysglycemia. Int J Behav Nutr Phys Act. 2020;17(1):1-14.

70. Chaudhry UA, Wahlich C, Fortescue R, Cook DG, Knightly R, Harris T. The effects of step-count monitoring interventions on physical activity: systematic review and meta-analysis of community-based randomised controlled trials in adults. Int $\mathrm{J}$ Behav Nutr Phys Act. 2020;17(1):1-16.

71. Kringle EA, Barone BG, Campbell G, McCue M, Terhorst L, Kersey J, et al. Influence of interventions on daily physical activity and sedentary behavior after stroke: a systematic review. PM \& R. 2019;12(2):186-201.

72. Patnode CD, Evans CV, Senger CA, Redmond N, Lin JS, Behavioral counseling to promote a healthful diet and physical activity for cardiovascular disease prevention in adults without known cardiovascular disease risk factors: updated evidence report and systematic review for the US Preventive Services Task Force. Jama. 2017;318(2):175-93.

73. O'Connor EA, Evans CV, Rushkin MC, Redmond N, Lin JS. Behavioral counseling to promote a healthy diet and physical activity for cardiovascular disease prevention in adults with cardiovascular risk factors: updated evidence report and systematic review for the US Preventive Services Task Force. JAMA. 2020;324(20):2076-94.

74. Gourlan M, Bernard P, Bortolon C, Romain AJ, Lareyre O, Carayol M, et al. Efficacy of theory-based interventions to promote physical activity. A meta-analysis of randomised controlled trials. Health Psychol Rev. 2016;10(1):50-66.

75. McEwan D, Harden SM, Zumbo BD, Sylvester BD, Kaulius M, Ruissen GR, et al. The effectiveness of multi-component goal setting interventions for changing physical activity behaviour: a systematic review and meta-analysis. Health Psychol Rev. 2016;10(1):67-88.

76. Ramôa Castro A, Oliveira NL, Ribeiro F, Oliveira J. Impact of educational interventions on primary prevention of cardiovascular disease: a systematic review with a focus on physical activity. Eur J Gen Pract. 2017;23(1):59-68.

77. Foster C, Richards J, Thorogood M, Hillsdon M. Remote and web 2.0 interventions for promoting physical activity [published online ahead of print, 2013 Sep 30]. Cochrane Database Syst Rev. 2013;9:CD010395. https://doi.org/10.1002/14651858. CD010395.pub2.

78. Richards J, Thorogood M, Hillsdon M, Foster C. Face-to-face versus remote and web 2.0 interventions for promoting physical activity. Cochrane Database Syst Rev. 2013;(9):CD010393. https://doi.org/10.1002/14651858.CD010393.pub2.

79. Whitlock EP, Orleans CT, Pender N, Allan J. Evaluating primary care behavioral counseling interventions: an evidence-based approach. Am J Prev Med. 2002;22(4):267-84. https://doi.org/10. 1016/s0749-3797(02)00415-4.

80. Willinger N, Steele J, Atkinson L, Liguori G, Jimenez A, Mann S, et al. Effectiveness of structured physical activity interventions through the evaluation of physical activity levels, adoption, retention, maintenance, and adherence rates: a systematic review and meta-analysis. J Phys Act Health. 2021;18(1):116-29. https://doi. org/10.1123/jpah.2019-0349.

81. Hobbs N, Godfrey A, Lara J, Errington L, Meyer TD, Rochester $\mathrm{L}$, et al. Are behavioral interventions effective in increasing physical activity at 12 to 36 months in adults aged 55 to 70 years? A systematic review and meta-analysis. BMC Med. 2013;11:75. https://doi.org/10.1186/1741-7015-11-75.

82. Arnett DK, Blumenthal RS, Albert MA, Buroker AB, Goldberger ZD, Hahn EJ, et al. 2019 ACC/AHA Guideline on the primary prevention of cardiovascular disease: executive summary: a report of the American College of Cardiology/American Heart Association Task Force on Clinical Practice Guidelines. Circulation. 2019;140(11):e563-95. https://doi.org/10.1161/CIR. 0000000000000677 This report provides the current recommended guidelines for the primary prevention of CVD.

83. Bays HE, Taub PR, Epstein E, Michos ED, Ferraro RA, Bailey $\mathrm{AL}$, et al. Ten things to know about ten cardiovascular disease risk factors. Am J Prev Cardiol. 2021;5:100149. https://doi.org/10. 1016/j.ajpc.2021.100149.

84. Williamson TM, Rouleau CR, Aggarwal SG, Arena R, Campbell TS. Bridging the intention-behavior gap for cardiac rehabilitation participation: the role of perceived barriers(). Disabil Rehabil. 2020;42(9):1284-91. https://doi.org/10.1080/09638288.2018. 1524519.

85. Sniehotta FF, Scholz U, Schwarzer R. Action plans and coping plans for physical exercise: a longitudinal intervention study in cardiac rehabilitation. Br J Health Psychol. 2006;11(Pt 1):23-37. https://doi.org/10.1348/135910705x43804.

86. Rhodes RE, Dickau L. Moderators of the intention-behaviour relationship in the physical activity domain: a systematic review. $\mathrm{Br}$ J Sports Med. 2013;47(4):215-25. https://doi.org/10.1136/ bjsports-2011-090411.

87. Ambrosetti M, Abreu A, Corrà U, Davos CH, Hansen D, Frederix I, et al. Secondary prevention through comprehensive cardiovascular rehabilitation: from knowledge to implementation. 2020 update. A position paper from the Secondary Prevention and Rehabilitation Section of the European Association of Preventive Cardiology. Eur J Prev Cardiol. 2020. https://doi.org/ $10.1177 / 2047487320913379$ This position paper provides the current recommendations for the key components and goals of cardiovascular rehabilitation.

88. Wasfy MM, Baggish AL. Exercise dose in clinical practice. Circulation. 2016;133(23):2297-313. https://doi.org/10.1161/ CIRCULATIONAHA.116.018093.

89. Caulin-Glaser T, Falko J, Hindman L, La Londe M, Snow R. Cardiac rehabilitation is associated with an improvement in Creactive protein levels in both men and women with cardiovascular disease. J Cardiopulm Rehabil Prev. 2005;25(6).

90. Cornelissen VA, Fagard RH, Coeckelberghs E, Vanhees L. Impact of resistance training on blood pressure and other cardiovascular risk factors. Hypertension. 2011;58(5):950-8. https://doi. org/10.1161/HYPERTENSIONAHA.111.177071.

91. McMahon SR, Ades PA, Thompson PD. The role of cardiac rehabilitation in patients with heart disease. Trends Cardiovasc Med. 2017;27(6):420-5. https://doi.org/10.1016/j.tcm.2017.02.005.

92. Yancy CW, Jessup M, Bozkurt B, Butler J, Casey DE Jr, Drazner $\mathrm{MH}$, et al. $2013 \mathrm{ACCF} / \mathrm{AHA}$ guideline for the management of heart failure: executive summary: a report of the American College of Cardiology Foundation/American Heart Association Task Force on practice guidelines. Circulation. 2013;128(16): 1810-52. https://doi.org/10.1161/CIR.0b013e31829e8807.

93. Thomas RJ, Balady G, Banka G, Beckie TM, Chiu J, Gokak S, et al. $2018 \mathrm{ACC} / \mathrm{AHA}$ clinical performance and quality measures for cardiac rehabilitation: a report of the American College of Cardiology/American Heart Association Task Force on performance measures. J Am Coll Cardiol. 2018;71(16):1814-37.

94. Anderson L, Taylor RS. Cardiac rehabilitation for people with heart disease: an overview of Cochrane systematic reviews. Cochrane Database Syst Rev. 2014;12. https://doi.org/10.1002/ 14651858.CD011273.pub2. 
95. Anderson L, Thompson DR, Oldridge N, Zwisler AD, Rees K, Martin N, et al. Exercise-based cardiac rehabilitation for coronary heart disease. Cochrane Database Syst Rev. 2016;1. https://doi. org/10.1002/14651858.CD001800.pub3.

96. Pavey TG, Taylor AH, Fox KR, Hillsdon M, Anokye N, Campbell JL, et al. Effect of exercise referral schemes in primary care on physical activity and improving health outcomes: systematic review and meta-analysis. BMJ. 2011;343:d6462. https://doi. org/10.1136/bmj.d6462.

97. Williams NH, Hendry M, France B, Lewis R, Wilkinson C. Effectiveness of exercise-referral schemes to promote physical activity in adults: systematic review. Br J Gen Pract. 2007;57(545):979-86.

98. Heath GW, Kolade VO, Haynes JW. Exercise is Medicine ${ }^{\mathrm{TM}}$ : a pilot study linking primary care with community physical activity support. Prev Med Rep. 2015;2:492-7. https://doi.org/10.1016/j. pmedr.2015.06.004.

99. Orrow G, Kinmonth A-L, Sanderson S, Sutton S. Effectiveness of physical activity promotion based in primary care: systematic review and meta-analysis of randomised controlled trials. BMJ. 2012;344:e1389. https://doi.org/10.1136/bmj.e1389.

100. Balady GJ, Ades PA, Bittner VA, Franklin BA, Gordon NF, Thomas RJ, et al. Referral, enrollment, and delivery of cardiac rehabilitation/secondary prevention programs at clinical centers and beyond. Circulation. 2011;124(25):2951-60. https://doi.org/ 10.1161/CIR.0b013e31823b21e2.

101. Santiago de Araújo Pio C, GSS C, Davies P, Taylor RS, Grace SL. Interventions to promote patient utilisation of cardiac rehabilitation. Cochrane Database Syst Rev. 2019;2. https://doi.org/10. 1002/14651858.CD007131.pub4.

102. Ozemek C, Phillips SA, Fernall B, Williams MA, Stamos TD, Bond $\mathrm{S}$, et al. Enhancing participation in cardiac rehabilitation: a question of proximity and integration of outpatient services. Curr Probl Cardiol. 2018;43:424-35. https://doi.org/10.1016/j. cpcardiol.2018.02.002.

103. Woodard CM, Berry MJ. Enhancing adherence to prescribed exercise: structured behavioral interventions in clinical exercise programs. J Cardiopulm Rehabil. 2001;21(4):201-209. https://doi. org/10.1097/00008483-200107000-00002.

104. Slovinec D'Angelo ME, Pelletier LG, Reid RD, Huta V. The roles of self-efficacy and motivation in the prediction of short- and longterm adherence to exercise among patients with coronary heart disease. Health Psychol. 2014;33(11):1344-53. https://doi.org/ 10.1037/hea0000094.

105. Woodgate J, Brawley LR. Self-efficacy for exercise in cardiac rehabilitation: review and recommendations. J Health Psychol. 2008;13(3):366-87. https://doi.org/10.1177/1359105307088141.

106. Oosenbrug E, Marinho RP, Zhang J, Marzolini S, Colella TJF, Pakosh M, et al. Sex differences in cardiac rehabilitation adherence: a meta-analysis. Can J Cardiol. 2016;32(11):131624. https://doi.org/10.1016/j.cjca.2016.01.036.

107. Barbaresko J, Rienks J, Nothlings U. Lifestyle indices and cardiovascular disease risk: a meta-analysis. Am J Prev Med. 2018;55(4):555-64.

108. U.S. Department of Agriculture and U.S. Department of Health and Human Services. Dietary Guidelines for Americans, 20202025. 9th Edition. Available at DietaryGuidelines.gov. 2020. Accessed 15 Mar 2021.

109. Duan Y, Shang B, Liang W, Du G, Yang M, Rhodes RE. Effects of eHealth-based multiple health behavior change interventions on physical activity, healthy diet, and weight in people with noncommunicable disease: systematic review and meta-analysis. J Med Internet Res. 2021;23(2):e23786.

110. Lara J, Evans EH, O’Brien N, Moynihan PJ, Meyer TD, Adamson $\mathrm{AJ}$, et al. Association of behaviour change techniques with effectiveness of dietary interventions among adults of retirement age: a systematic review and meta-analysis of randomized controlled trials. BMC Med. 2014;12:177.

111. Cradock KA. Olaighin G, Finucane FM, McKay Rhyann, Quinlan LR, Martin Ginis KA, Gainforth HL. Diet behavior change techniques in type 2 diabetes: a systematic review and meta-analysis. Diabetes Care. 2017:40:1800-10.

112. Angell SY, McConnell MV, Anderson CAM, Bibbins-Domingo K, Boyle DS, Capewell S, et al. The American Heart Association 2030 Impact Goal: a presidential advisory from the American Heart Association. Circulation. 2020;141(9):e120-38. https://doi. org/10.1161/cir.0000000000000758.

113. Hall G, Laddu DR, Phillips SA, Lavie CJ, Arena R. A tale of two pandemics: how will COVID-19 and global trends in physical inactivity and sedentary behavior affect one another? Prog Cardiovasc Dis. 2020;64:108-10. https://doi.org/10.1016/j.pcad. 2020.04.005.

114. Duff OM, Walsh DM, Furlong BA, O'Connor NE, Moran KA, Woods CB. Behavior change techniques in physical activity ehealth interventions for people with cardiovascular disease: systematic review. J Med Internet Res. 2017;19(8):e281. https://doi. org/10.2196/jmir.7782.

115. Albright CL, Pruitt L, Castro C, Gonzalez A, Woo S, King AC. Modifying physical activity in a multiethnic sample of lowincome women: one-year results from the IMPACT (Increasing Motivation for Physical ACTivity) project. Ann Behav Med. 2005;30(3):191-200. https://doi.org/10.1207/ s15324796abm3003_3.

Publisher's Note Springer Nature remains neutral with regard to jurisdictional claims in published maps and institutional affiliations. 